\title{
Impact of high emissivity paint layer on thermographic measurements of electronic circuits thermal impedance
}

by M. Kałuża

\begin{abstract}
*Institute of Electronics, Lodz University of Technology, 93-005, Wolczanska Str., Lodz, Poland,
\end{abstract} marcin.kaluza@p.lodz.pl

\begin{abstract}
The aim of this paper is to present the impact of a paint layer - often added on the surface of an integrated circuit due to low emissivity of metallic elements - on the results of thermal impedance measurements made with an infrared camera. A thick film resistor on alumina is used as a test device. Its thermal power step response is measured with a cooled thermographic camera for configurations without any paint and with paint layers of different thickness. Next, the measurement results are compared and the impact of the paint is evaluated.
\end{abstract}

\section{Introduction}

Elevated temperature is the dominant cause of electronic systems failures, accounting for $55 \%$ of them [1]. Thus, thermal characterization of electronic circuits is a must. One of principal methods of describing their thermal properties is the thermal impedance approach. The mathematical foundations for its measurements were described in [2] and reference measurement methods were laid down in the JEDEC JESD51-1 and JESD51-2 standards [3-4]. The thermal impedance is obtained based on measurements of circuit temperature rise in response to a power step, from time zero to the moment when a thermal steady state is obtained. The method assumes thermal system linearity, temperature measurement at the heat source (or close to it) and a quasi 1-D heat flow.

The thermal impedance of the tested circuit can by presented in the form of a Nyquist plot or after mathematical transformation as a thermal constant spectrum or so called structure functions. A typical measurement approach consist in using a semiconductor diode or transistor as temperature sensors only, or as both a heat source and a sensor [5]. Instead, in [6] the authors demonstrated the possibility of using thermographic measurements of a silicon chip temperature rise in order to obtain its thermal impedance curve. Because of low emissivity value of metallic interconnects and semiconductor chip surface, thermographic measurements of a chip temperature rise often requires to apply a paint layer on its surface to increase its emissivity [7]. Such a paint layer will affect the results of thermal impedance measurements.

\section{Measurement setup}

A custom designed and manufactured thick film resistor made on a $50 \times 50 \times 0.6 \mathrm{~mm}$ alumina plate, mounted on a ICKPGA21X21 heatsink from Fischer Elektronik, was used as a test device. The heatsink, with dimensions of $53.3 \mathrm{x}$ $53.3 \times 16.5 \mathrm{~mm}$ matching the alumina plate size, was attached to the resistor using a Fischer Elektronik silicon thermal pad with a double-sided adhesive layer. Its role was not only to provide good heat conduction between the resistor and the heatsink, but also a mechanically stable connection during manipulations when preparing the test device for measurements. For the same reasons, after first tests, the use of thermal paste was ruled out, as when using it, the resistor had tendency to move on the heatsink surface, making it difficult to ensure repeatable measurement conditions. The resistor assembly used during tests is shown in Fig. 1. For clarity, later in the text the black resistive layer shown in the picture will be called resistor, whereas the entire device under test will be called device or resistor assembly.

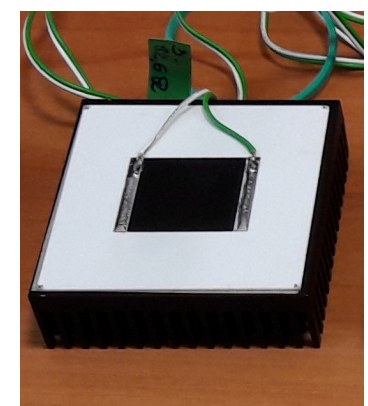

Fig. 1. Tested thick-film resistor assembly 
The resistor assembly was placed on a thick steel plate inside a heat test chamber to protect it from any external influence, which could affect the measurement process, and was connected to an external power source. The power source was activated using a T3Ster transient thermal tester system. A fast cooled thermographic camera Cedip Titanium 560M, placed above the upper port of the test chamber, was used to record the device heating-up process. To synchronize the heating and measurement processes, the thermographic sequence was time-stamped by the T3Ster system when switching on the heating power. The entire measurement setup is shown in Fig. 2.

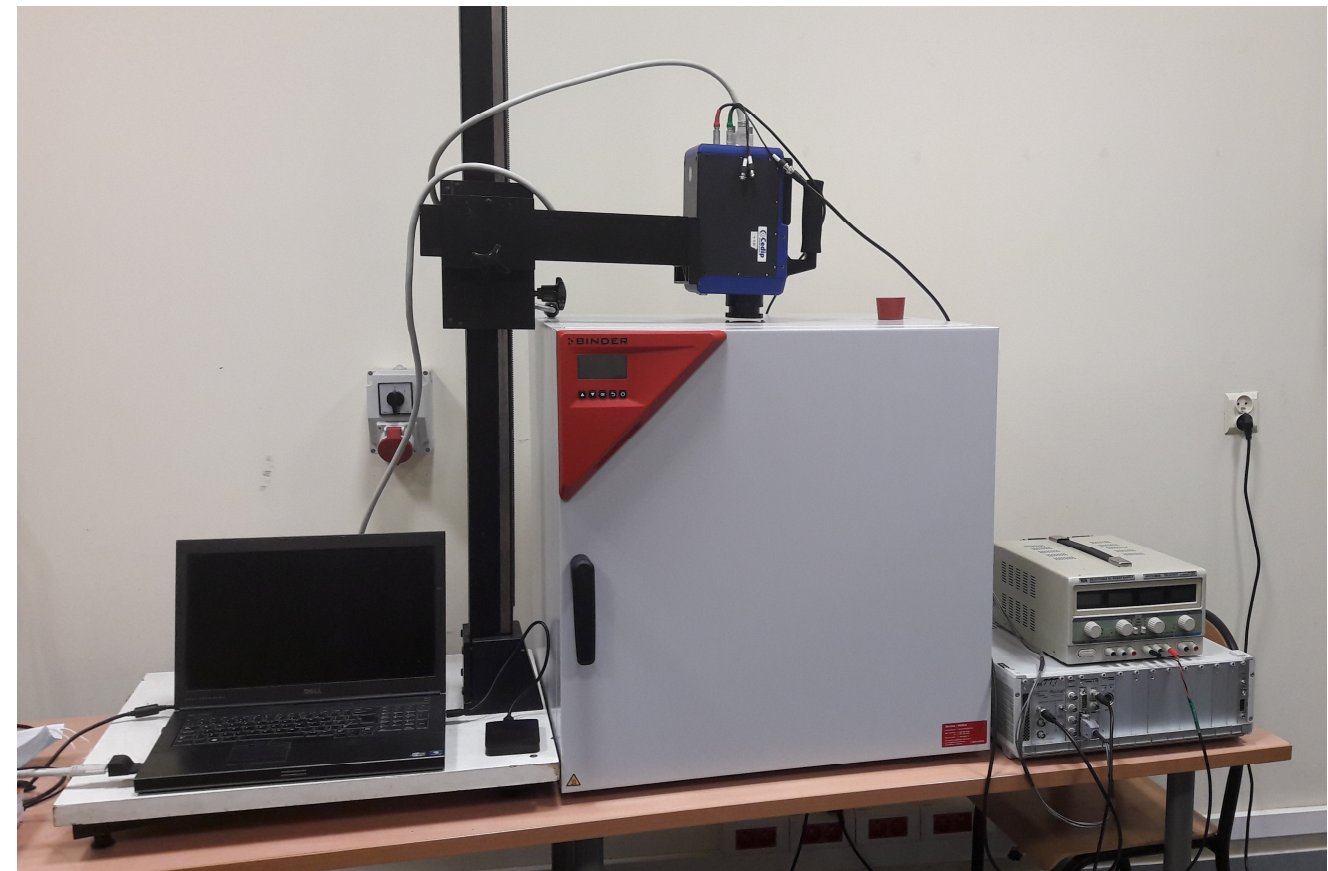

Fig. 2. Measurement setup consisting of a cooled thermographic camera, a heat test chamber, a power source and a T3Ster transient thermal tester

The measurement process was repeated for the resistor without any paint layer, with a single, a double and a triple paint layer. To avoid creating a multilayer paint structure, for each of the three painted resistor configurations, the resistive structure was first cleaned and next the required number of paint layers was deposited. Based on preliminary tests, the paint was applied only to the central $20 \times 20 \mathrm{~mm}$ area containing the resistor itself. Covering a wider area created a lateral heat diffusion layer, affecting the measurements - a problem increasing with the paint film thickness. The black mat paint used for experiments was chosen out of six tested aerosol sprays. A high emissivity value, a viscosity allowing to create a thin flat surface free of air bubbles and easy removal and cleaning using acetone were required. For all four resistor assembly configurations, the thickness of the unpainted and painted resistor was measured with a Mitutoyo micrometric sensor, using the alumina surface as reference. Based on those measurements, the paint film thickness for single, double and triple layer configuration was calculated.

\section{Measurement results}

The measured heating-up step response curves were imported into the T3Ster Master software, and the resistor assembly thermal time constants spectrum and so called cumulative structure functions were calculated for each device configuration. The spectra are shown in Fig. 3 for all 4 tested configurations. 


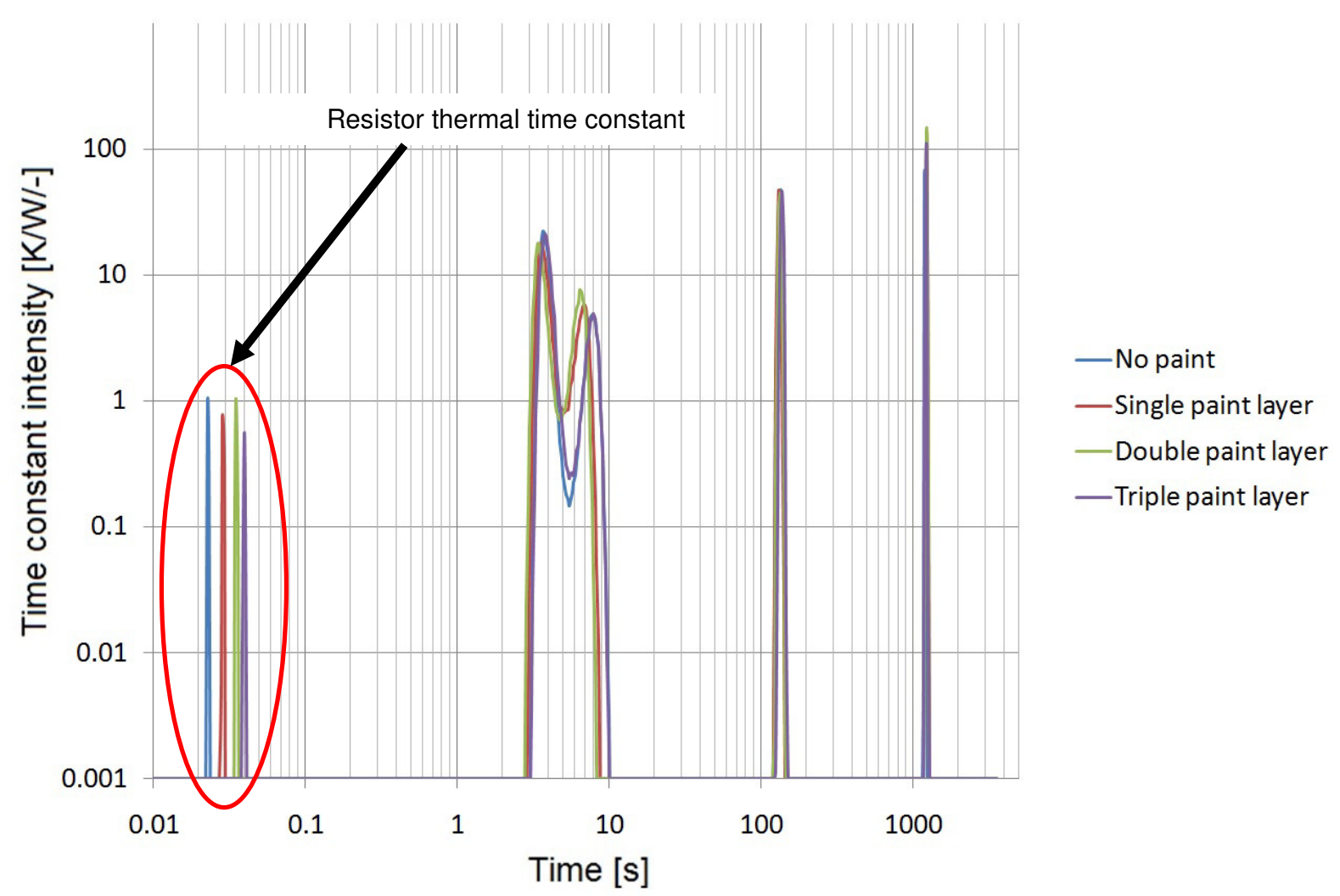

Fig. 3. Measured thermal time constant distribution of the thick-film test resistor assembly for the configuration without paint (blue curve), with a single paint layer (red curve), with a double paint layer (green curve) and with a triple paint layer covering its surface (violet curve)

Five different time constants were identified, $\tau_{1}$ - the resistor thermal time constant, $\tau_{2}$ - the alumina plate thermal time constant, $\tau_{3}$ - the thermal pad thermal time constant, $\tau_{4}$ - the heatsink thermal time constant and $\tau_{5}$ representing heat dissipation to the steel plate/ambient. The measured values of those time constants are given in Table 1.

Table 1. Measured thermal time constants values

\begin{tabular}{|c|c|c|c|c|c|}
\hline Thermal time & $\tau_{1}$ & $\tau_{2}$ & $\tau_{3}$ & $\tau_{4}$ & $\tau_{5}$ \\
\hline $\begin{array}{l}\text { Test device } \\
\text { configuration }\end{array}$ & resistor & alumina plate & thermal pad & heatsink & $\begin{array}{c}\text { steel } \\
\text { plate/ambient }\end{array}$ \\
\hline No paint & 0.023 & 3.71 & 7.76 & 134 & 1202 \\
\hline Single paint layer & 0.029 & 3.63 & 6.92 & 132 & 1230 \\
\hline Double paint layer & 0.035 & 3.48 & 6.45 & 134 & 1230 \\
\hline Triple paint layer & 0.040 & 3.80 & 7.94 & 138 & 1230 \\
\hline
\end{tabular}

Whereas there are some differences for the $\tau_{2}-\tau_{5}$ time constants between the four tested resistor configurations, they are all within \pm 1 discrete time step, for a given constant, for all configurations. One can assume that for the $\tau_{2}-\tau_{5}$ time constants similar results were obtained and were not affected by the paint layer. The situation is different for $\tau_{1}$, which represents the resistor thermal time constant. A clear correlation between paint film thickness and time constant value can be seen. The layer of paint acts clearly as a delay line. The comparison of the $\tau_{1}$ values with the measured paint layer thicknesses is given in Table 2 . 
10.21611/qirt.2020.147

$15^{\text {th }}$ Quantitative InfraRed Thermography Conference, 6 - 10 July 2020, Porto, Portugal

Table 2. Measured $\tau_{1}$ thermal time constant values compared with the measured paint layer thickness

\begin{tabular}{|l|c|c|}
\hline $\begin{array}{l}\text { Test device } \\
\text { configuration }\end{array}$ & Resistor thermal time constant $\boldsymbol{\tau}_{\mathbf{1}}$ [ms] & Paint layer thickness [ $\boldsymbol{\mu m}]$ \\
\hline No paint & 23 & 0 \\
\hline Single paint layer & 29 & 15 \\
\hline Double paint layer & 35 & 30 \\
\hline Triple paint layer & 40 & 40 \\
\hline
\end{tabular}

To get a better insight into the effects of adding a paint layer on the $\tau_{1}$ time constant of the tested resistor, the cumulative structure functions were used. A cumulative structure function is a graphic representation of the 1-D equivalent thermal RC network of the measured system, and shows the thermal resistance and capacitance values of the heat flow path, from source to the ambient. A magnified part of the structure function curves representing the thermal properties of the resistor is shown in Fig. 4.

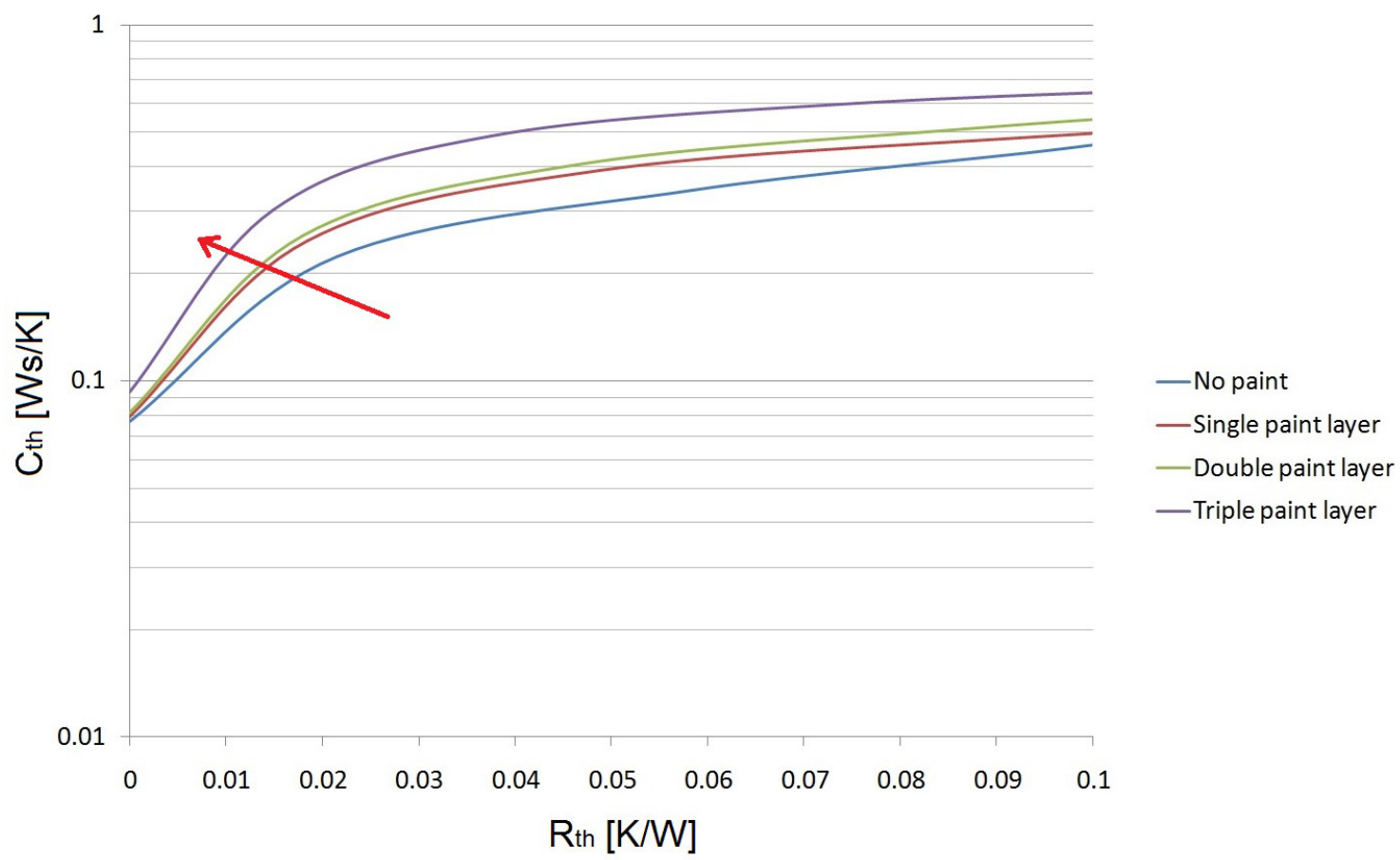

Fig. 4. Magnified part of the cumulative structure function curves representing the thermal properties of the resistor layer of the tested assembly for the configuration without paint (blue curve), with a single paint layer (red curve), with a double paint layer (green curve) and with a triple paint layer (violet curve) covering the resistor surface

Based on the presented curves, one can see that the main effect of adding paint was to increase the measured effective thermal capacitance value of the resistor, thus increasing the value of its time constant.

\section{Conclusions}

To test the impact of a paint layer on the results of thermal impedance measurements made with an infrared camera, a custom made thick film resistor on alumina was mounted on a heatsink and its power step thermal response was measured for a configuration without any paint, with a $15 \mu \mathrm{m}$ thick paint layer, a $30 \mu \mathrm{m}$ thick paint layer and a $40 \mu \mathrm{m}$ thick paint layer covering the resistor.

In the first case, a $23 \mathrm{~ms}$ thermal time constant was obtained for the unpainted resistor. Adding a single $15 \mu \mathrm{m}$ thick paint layer increased that value to $29 \mathrm{~ms}$, whereas doubling the paint layer thickness to $30 \mu \mathrm{m}$ added another 6 ms, giving a $35 \mathrm{~ms}$ thermal time constant. A further increase of the paint thickness by $10 \mu \mathrm{m}$ increased the time constant by another $5 \mathrm{~ms}$. Based on the obtained results one can conclude, that if conducting thermal impedance thermographic measurements of electronic circuits, where millisecond thermal time constants are obtained, the impact of a paint layer added atop of the circuit has to be taken into account for short time constants. As was demonstrated, based on 
measurements, the paint layer did not affect the longer time constants of the tested circuit, thus thermography can be used for thermal impedance measurements of small electronic circuits, even if paint has to be added on their surface to solve the problem of low emissivity value of the heat source.

Based on [8-10], thermal properties, and especially thermal conductivity of different paints can vary considerably, thus further investigation of the problem, including experiments using other geometries of test circuits, will be required.

\section{REFERENCES}

[1] A. Poppe, "Thermal Measurements and Modelling. The Transient and Multichip Issues", $11^{\text {th }}$ THERMINIC Workshop, Belgirate, Italy, September 27-30, 2005.

[2] V. Szekely, T. Van Bien, "Fine structure of heat flow path in semiconductor measurement and identification method", Solid State Electronics, vol. 31, pp. 1363-1368, 1988.

[3] JEDEC JESD51-1 standard

[4] JEDEC JESD51-2 standard

[5] Mentor Graphics T3Ster User Manual

[6] I. Papagiannopoulos, V. Chatziathanasiou, A. Hatzopoulos, M. Kaluza, B. Wiecek and G. De Mey, "Thermal analysis of integrated spiral inductors", Infrared Physics \& Technology, vol. 56, pp. 80-84, January 2013.

[7] M. Kałuża, B. Więcek, G. De Mey, A. Hatzopoulos and V. Chatziathanasiou, "Thermal impedance measurement of integrated inductors on bulk silicon substrate", Microelectronics Reliability, vol. 73, pp. 54-59, June 2017.

[8] O. Raghu, "Realization of a Scanning Photoacoustic Technique: Thermal Properties of Bulk and Film Samples", Cochin University of Science and Technology, 2007.

[9] M. Susa, X. Maldague, S. Svaic, I. Boras and A. Bendada, "The influence of surface coatings on the differences between numerical and experimental results for samples subject to a pulse thermography examination", $9^{\text {th }}$ International Conference on Quantitative InfraRed Thermography, QIRT 2008, July 2-5, 2008, Krakow - Poland.

[10] D. Legaie, H. Pron, C. Bissieux and V. Blain, "Thermographic application of black coatings on metals", $9^{\text {th }}$ International Conference on Quantitative InfraRed Thermography, QIRT 2008, July 2-5, 2008, Krakow - Poland. 